- This study has a more representative sample of pregnant women in the UK when compared with previous studies investigating associations between periodontal disease and adverse pregnancy outcome.

- Periodontal disease did not appear to be a risk factor for premature or low birth weight birth in their population.

- Periodontal disease does appear to be associated with miscarriage between 12 and 24 weeks gestation, even after controlling for other risk factors of poor pregnancy outcome. It is not yet known whether treating periodontal disease in pregnancy can reduce the risk of miscarriage.

\title{
A prospective study to investigate the relationship between periodontal disease and adverse pregnancy outcome
}

\author{
S. Moore, ${ }^{1}$ M. Ide, ${ }^{2}$ P. Y. Coward, ${ }^{3}$ M. Randhawa, ${ }_{1}^{4}$ E. Borkowska, ${ }^{5}$ R. Baylis ${ }^{6}$ and R. F. Wilson ${ }^{7}$
}

\author{
Objective This study aimed to investigate a relationship between \\ maternal periodontal disease and preterm birth, low birth weight and \\ late miscarriage. \\ Design Prospective study in a single centre. \\ Setting Guy's and St Thomas' Hospital Trust, London, UK between \\ August 1998 and July 2001.
}

Subjects and Methods Pregnant women were recruited on attending an ultrasound scan at approximately 12 weeks of pregnancy. Subjects completed a questionnaire and underwent periodontal examination. Main outcome measures Plaque and bleeding scores, pocket probing depth and loss of attachment. Pregnancy outcome data was collected retrospectively, including gestational age and birth weight at delivery. Results Data were collected for 3,738 subjects. Regression analysis indicated that there were no significant relationships between the severity of periodontal disease and either preterm birth (PTB) or low birth weight (LBW). In contrast, there did appear to be a correlation between poorer periodontal health and those that experienced a late miscarriage.

Conclusions There was no association between either preterm birth or low birth weight and periodontal disease in this population. There is evidence of a correlation between markers of poorer periodontal health and late miscarriage.

\section{INTRODUCTION}

Previous studies have found evidence of an association between severe periodontal disease during pregnancy and premature (or preterm) birth (PTB). ${ }^{1-3}$ However a recent investigation in a UK

\footnotetext{
'Specialist Registrar, Restorative Dentistry, ${ }^{2}$ Senior Lecturer and Honorary Consultant, ${ }^{4}$ Research Midwife, ${ }^{5}$ Clinical Demonstrator, ${ }^{6}$ Clinical Demonstrator, Periodontology and Preventive Dentistry, Floor 21 Guy's Tower, Guy's, King's, and St. Thomas' Dental Institute, King's College, London SE1 9RT; ${ }^{3}$ Senior Scientific Officer, ${ }^{7}$ Senior Lecturer, Dental Clinical Research, Floor 17 Guy's Tower, Guy's, King's, and St. Thomas' Dental Institute, King's College, London SE1 9RT

Correspondence to: Dr Suzanne Moore, RDU, Floor 26 Guy's Tower, GKT Dental Institute London Bridge SE1 9RT

Email:Suzanne.Farrell@gstt.sthames.nhs.uk
}

\section{Refereed paper}

Received 05.05.03; Accepted 07.11.03

doi:10.1038/sj.bdj.4811620

๑ British Dental Journal 2004; 197: 251-258 population failed to find such strong evidence ${ }^{4}$ and there is currently a lack of published prospective studies in this field. ${ }^{5}$ Preterm birth can be defined as birth before 37 weeks gestation and is associated with a high rate of perinatal mortality and morbidity. ${ }^{6}$ It has also been shown that babies born prematurely are more prone to future neurological problems ${ }^{7}$ and perhaps cardiovascular and respiratory disease in later life. ${ }^{8}$ Preterm birth can be more extreme, such as delivery at less than 32 weeks gestation: ${ }^{9}$ this has been shown to increase further the risk of adverse sequelae. If birth occurs before 24 weeks of gestation it is termed miscarriage as the fetus is categorised as non-viable ${ }^{10}$ but can still be regarded as a very extreme form of preterm birth. This should be differentiated from early miscarriage at less than 12 weeks gestation which generally has a different aetiology. ${ }^{11}$

Adverse pregnancy outcome is multifactorial and risk factors include increased age, non-White ethnicity, low socioeconomic status, smoking, malnutrition, multiple gestation, previous poor obstetric outcome and current or previous genito-urinary infection. ${ }^{12}$ If there is an association between maternal periodontal disease and adverse pregnancy outcome, there are a number of potential explanatory hypotheses. Several factors that contribute to risk and are common to both periodontal disease and poor pregnancy outcome include age, ${ }^{12}$ ethnicity, socioeconomic status ${ }^{13}$ and smoking status. ${ }^{14-16}$ It is therefore important to allow for these confounding factors when investigating a possible relationship between the two conditions. Alternatively periodontal disease could cause preterm birth by providing a source of infection stimulating immune and inflammatory responses, producing inflammatory mediators that could prematurely stimulate the onset of labour.

Therefore, the aim of this prospective study was to investigate the relationship between maternal periodontal disease and adverse pregnancy outcome in a population delivering primarily at Guy's and St Thomas' Hospital Trust.

\section{MATERIALS AND METHODS}

This study was approved by the Guy's Hospital Trust Local Ethical Committee. Pregnant women were recruited when they attended Guy's Hospital for a nuchal translucency scan at approximately 12 weeks gestational age. Patients were referred for this ultrasound investigation by their general practitioners (GPs), midwives or obstetricians. The nuchal translucency scan is used to assess the 


\begin{tabular}{|c|c|c|c|c|c|c|}
\hline & $\begin{array}{c}\text { All subjects, } \\
n=3,738\end{array}$ & $\begin{array}{c}\text { Non-preterm } \\
\text { delivery, } \\
n=3,452\end{array}$ & $\begin{array}{l}\text { Preterm } \\
\text { delivery, } \\
n=286\end{array}$ & $\begin{array}{c}P \text { value } \\
\text { preterm vs } \\
\text { non-preterm }\end{array}$ & $\begin{array}{c}\text { Extreme } \\
\text { preterm } \\
\text { delivery, } n=112\end{array}$ & $\begin{array}{c}P \text { value } \\
\text { extreme } \\
\text { preterm vs } \\
\text { non-preterm }\end{array}$ \\
\hline Age, years, mean (SD) & $29.9(5.5)$ & $29.8(5.5)$ & $30.1(5.7)$ & $0.387^{*}$ & $30.8(5.7)$ & $0.072^{*}$ \\
\hline \multicolumn{7}{|l|}{ Ethnicity, $n(\%)$} \\
\hline White & $2,330(62.3)$ & $2,191(63.4)$ & $139(48.6)$ & \multirow{3}{*}{$<0.001$} & $34(30.4)$ & \multirow{3}{*}{$<0.001$} \\
\hline Black & $1,055(28.2)$ & $935(27.1)$ & $120(42.0)$ & & $68(60.7)$ & \\
\hline Other & $353(9.5)$ & $326(9.4)$ & $27(9.4)$ & & $10(8.9)$ & \\
\hline \multicolumn{7}{|l|}{ Socioeconomic group, $n(\%)$} \\
\hline $1 / 2$ & $1,994(53.3)$ & $1,860(53.8)$ & $134(46.9)$ & \multirow{3}{*}{0.037} & $50(44.6)$ & \multirow{3}{*}{0.140} \\
\hline $3 / 4 / 5$ & $1,422(38.0)$ & $1,303(37.8)$ & $119(41.6)$ & & $51(45.6)$ & \\
\hline others & $322(8.6)$ & $289(8.4)$ & $33(11.5)$ & & $11(9.8)$ & \\
\hline Smokers in pregnancy, $n(\%)$ & $543(14.5)$ & $497(14.4)$ & $46(16.1)$ & 0.242 & $15(13.4)$ & 0.448 \\
\hline Alcohol in pregnancy, $n(\%)$ & $614(16.4)$ & $565(16.4)$ & $49(17.1)$ & 0.395 & $18(16.1)$ & 0.529 \\
\hline First pregnancy?, $n(\%)$ & $1,749(46.7)$ & $1,619(46.9)$ & $128(44.8)$ & 0.262 & $41(36.6)$ & 0.019 \\
\hline Urinary tract infection $1^{\text {st }}$ trimester, $n(\%)$ & $327(8.8)$ & $298(8.6)$ & $29(10.1)$ & 0.222 & $17(15.2)$ & 0.018 \\
\hline Antibiotics in $1^{\text {st }}$ trimester, $n(\%)$ & $457(12.2)$ & $413(12.0)$ & $44(15.4)$ & 0.058 & $24(21.4)$ & 0.004 \\
\hline Medication in $1^{\text {st }}$ trimester, $n(\%)$ & $1,175(31.4)$ & $1,068(30.9)$ & $107(37.4)$ & 0.015 & $45(40.2)$ & 0.026 \\
\hline Previous preterm delivery, $n(\%)$ & $155(4.2)$ & $129(3.7)$ & $26(9.1)$ & $<0.001$ & $10(8.9)$ & 0.011 \\
\hline Previous miscarriage/stillbirth, $n(\%)$ & 705 (18.9) & $634(18.4)$ & $71(24.8)$ & 0.006 & $40(35.7)$ & $<0.001$ \\
\hline
\end{tabular}

nuchal ligament in the neck of the fetus as a risk factor for Down's Syndrome. ${ }^{17}$ Subjects were excluded from the study if they were less than 10 or more than 15 weeks pregnant, if they had a current multiple pregnancy, or if they required prophylactic antibiotics before dental treatment.

Informed consent was obtained and an examiner-administered questionnaire was completed. This questionnaire was designed to gather demographic details, pregnancy and medical history, health behaviour, dental experience and smoking status. Socioeconomic status was classified according to the Standard Occupational Classification of the Office of Population Censuses and Surveys (1991, 1995). The aim of the questionnaire was to collect information on as many of the known risk factors for adverse pregnancy outcome as possible.

The periodontal examination was performed with the patient supine on a hospital bed. This examination has been described in detail previously. ${ }^{18}$ In brief, a full mouth, two sites per tooth assessment was performed for the presence of plaque (presence or absence), probing depth $(\mathrm{mm})$, loss of periodontal attachment $(\mathrm{mm})$ and bleeding on probing (presence or absence). Data were recorded orally onto a cassette tape and then transcribed to a clinical examination sheet.

Subjects were informed of any periodontal problems and advised to visit a dentist if necessary. Oral hygiene instruction was not given to the subjects, however packs containing a toothbrush, toothpaste and oral hygiene leaflet (courtesy of Colgate Palmolive, UK) were issued to all women.

\section{Pregnancy outcome data collection}

Collection of pregnancy outcome information was performed by a 'research midwife'. Data collected included: gestational age at delivery; birth weight and gender of baby; onset of delivery (spontaneous or induced); any relevant complications such as evidence of a genito-urinary infection; medication administered. Different protocols for data collection were followed by the research midwife according to where the subject delivered their baby. These mainly included the Guys' and St Thomas' Hospital Trust maternity hospital database - Terranova (Healthware, UK) or subjects' general medical practioners.

\section{Statistical methods}

Data were analysed using SPSS (Statistical Package for Social Sciences for Unix, SPSS Inc., Chicago, Illinois) and Stata 7 for PC (Stata Corporation, Texas).

The subjects' age and body mass index were calculated from data provided in the baseline questionnaire. Ethnicity was classified by the subject into one of eleven groups after completing the consent form: White; Black Caribbean; Black African; Black other; Indian; Pakistani; Bangladeshi; Chinese; Asian other; and Other (including those of mixed race). The number of subjects from the non-White and non-Black ethnic groups was small. Therefore, when analysing ethnicity, some of the groups were combined, producing: White; Black; and Other. Socioeconomic status was recalculated as the highest socioeconomic group of either the mother or her partner (if the data were available). For some of the analyses, socioeconomic groups were combined: groups 1 and 2; 3, 4 and 5; and all other groups (including unemployed, student, housewife/ husband, missing). Information concerning health behaviour, such as smoking status and alcohol consumption during pregnancy, and medical/previous pregnancy history data, was taken from selfreport at the 12-week questionnaire and so related to the first trimester of pregnancy. Periodontal data from all sites (mesial and mid sites) were analysed, in addition to that from mesial sites alone. Probing depth (PD) and loss of attachment (LA) were assessed both by full mouth mean values and the percentage of sites with either PD or LA at or above given cut-off values. All periodontal data were found to be non-normally distributed and so were summarised by median and interquartile range (IQR) and tested by Mann Whitney- $U$ tests.

Gestational age and birth weight at delivery were chosen as the two main pregnancy outcome characteristics. In addition, adverse pregnancy outcome was categorised into outcome categories. For preterm birth, spontaneous birth at: less than 37 weeks gestation (preterm birth); less than 32 weeks gestation (extreme preterm birth). Low birth weight was defined as birth weight less than 2,500 g. Late miscarriage (between 12 and 24 weeks gestation), intra-uterine death (IUD) (at 24 weeks gestation or over) or stillbirth (10) were combined into the group termed 'miscarriage'. 
Table 2 Demographic and obstetric data for those that experienced a low birth weight birth (less than $2500 \mathrm{~g}$ birth weight) and those that did not $(2,500 \mathrm{~g}$ birth weight or over) and for those that experienced a late miscarriage and those that did not (37 weeks of gestation or over) $\left(P\right.$ value by exact chi-square test except ${ }^{*} t$-test)

\begin{tabular}{|c|c|c|c|c|c|c|}
\hline & $\begin{array}{c}\text { Non- low birth } \\
\text { weight delivery, } \\
n=3,492\end{array}$ & $\begin{array}{l}\text { Low birth } \\
\text { weight delivery, } \\
n=246\end{array}$ & $\begin{array}{l}\text { Pvalue } \\
\text { LBW vs } \\
\text { non-LBW }\end{array}$ & $\begin{array}{c}\text { Non-preterm } \\
\text { delivery, } \\
n=3,452\end{array}$ & $\begin{array}{c}\text { Miscarriage } \\
n=49\end{array}$ & $\begin{array}{c}P \text { value } \\
\text { miscarriage } \\
\text { vs non-preterm }\end{array}$ \\
\hline Age, years, mean (SD) & $29.9(5.5)$ & $29.9(6.0)$ & $0.927^{*}$ & $29.8(5.5)$ & $31.9(5.7)$ & $0.012^{*}$ \\
\hline \multicolumn{7}{|l|}{ Ethnicity, $n(\%)$} \\
\hline White & $2,211(63.3)$ & $119(48.4)$ & \multirow{3}{*}{$<0.001$} & $2,191(63.4)$ & $13(26.5)$ & \multirow{3}{*}{$<0.001$} \\
\hline Black & $948(27.1)$ & $107(43.5)$ & & $935(27.1)$ & $30(61.2)$ & \\
\hline Other & $333(9.6)$ & $20(8.1)$ & & $326(9.4)$ & $6(12.2)$ & \\
\hline \multicolumn{7}{|l|}{ Socioeconomic group, $n(\%)$} \\
\hline $1 / 2$ & $1,887(54.0)$ & $107(43.5)$ & \multirow{3}{*}{0.005} & $1,860(53.8)$ & $18(36.7)$ & \multirow{3}{*}{.044} \\
\hline $3 / 4 / 5$ & $1,308(37.5)$ & $114(46.3)$ & & $1,303(37.8)$ & $25(51.0)$ & \\
\hline Others & $297(8.5)$ & $25(10.2)$ & & $289(8.4)$ & $6(12.2)$ & \\
\hline Smokers in pregnancy, $n(\%)$ & 495 (14.2) & $48(19.5)$ & 0.016 & $497(14.4)$ & $7(14.3)$ & 0.590 \\
\hline Alcohol in pregnancy, $n(\%)$ & $577(16.5)$ & $37(15.0)$ & 0.307 & $565(16.4)$ & $7(14.3)$ & 0.439 \\
\hline First pregnancy?, $n(\%)$ & $1,627(46.6)$ & $120(48.8)$ & 0.274 & $1,619(46.9)$ & $15(30.6)$ & 0.016 \\
\hline Urinary tract infection $1^{\text {st }}$ trimester, $n(\%)$ & $237(6.8)$ & $40(16.3)$ & $<0.001$ & $298(8.6)$ & $6(12.2)$ & 0.249 \\
\hline Antibiotics in $1^{\text {st }}$ trimester, $n(\%)$ & $402(11.5)$ & $55(22.4)$ & $<0.001$ & $413(12.0)$ & $13(26.5)$ & 0.005 \\
\hline Medication in $1^{\text {st }}$ trimester, $\mathrm{n}(\%)$ & $1,083(31.0)$ & $92(37.4)$ & 0.023 & $1,068(30.9)$ & $24(49.0)$ & 0.007 \\
\hline Previous preterm delivery, $\mathrm{n}(\%)$ & $129(3.7)$ & $26(10.6)$ & $<0.001$ & $129(3.7)$ & $6(12.2)$ & 0.011 \\
\hline Previous miscarriage/stillbirth, $\mathrm{n}(\%)$ & $644(18.4)$ & $61(24.8)$ & 0.010 & $634(18.4)$ & $17(34.7)$ & 0.005 \\
\hline
\end{tabular}

Table 3 Periodontal data for subjects that experienced a preterm birth (less than 37 weeks gestation) or an extreme preterm birth (less than 32 weeks gestation) and those that did not (37 weeks of gestation or over).

\begin{tabular}{|c|c|c|c|c|c|}
\hline & $\begin{array}{c}\text { Non-preterm delivery, } \\
n=3,452\end{array}$ & $\begin{array}{l}\text { Preterm delivery, } \\
\quad n=286\end{array}$ & $\begin{array}{c}P \text { value } \\
\text { preterm vs } \\
\text { non-preterm } \\
\end{array}$ & $\begin{array}{l}\text { Extreme preterm } \\
\text { delivery, } n=112\end{array}$ & $\begin{array}{c}P \text { value } \\
\text { extreme preterm } \\
\text { vs non-preterm }\end{array}$ \\
\hline$\%$ of sites with plaque, median $(\mathrm{IQR})^{+}$ & $53(34-72)$ & $55(37-74)$ & 0.227 & $53(36-78)$ & 0.564 \\
\hline Mesial sites only & $68(44-89)$ & $69(48-89)$ & 0.433 & $69(45-91)$ & 0.691 \\
\hline Mean $\mathrm{PD}^{\ddagger}, \mathrm{mm}$, median (IQR) & $2.03(1.82-2.27)$ & $2.04(1.86-2.27)$ & 0.313 & $2.06(1.92-2.24)$ & 0.106 \\
\hline Mesial sites only & $2.44(2.19-2.76)$ & $2.44(2.23-2.73)$ & 0.412 & $2.48(2.31-2.74)$ & 0.106 \\
\hline Mean $L^{\alpha}{ }^{\alpha}, \mathrm{mm}$, median (IQR) & $0.23(0.09-0.45)$ & $0.21(0.08-0.47)$ & 0.831 & $0.23(0.10-0.48)$ & 0.508 \\
\hline Mesial sites only & $0.20(0.04-0.48)$ & $0.21(0.04-0.52)$ & 0.557 & $0.29(0.07-0.53)$ & 0.271 \\
\hline$\%$ of sites $\mathrm{BOP} \beta$, median (IQR) & $22(11-37)$ & $21(11-35)$ & 0.622 & $20(10-40)$ & 0.521 \\
\hline Mesial sites only & $29(14-46)$ & $28(14-46)$ & 0.722 & $25(14-48)$ & 0.795 \\
\hline \% of sites PD $\geq 4$ mm, median (IQR) & $4(2-9)$ & $4(2-9)$ & 0.790 & $4(2-10)$ & 0.812 \\
\hline Mesial sites only & $4(3-18)$ & $7(3-18)$ & 0.626 & $7(3-18)$ & 0.997 \\
\hline$\%$ of sites PD $\geq 5$ mm, median (IQR) & $0(0-4)$ & $0(0-3)$ & 0.088 & $0(0-3)$ & 0.190 \\
\hline Mesial sites only & $0(0-7)$ & $0(0-7)$ & 0.072 & $0(0-7)$ & 0.178 \\
\hline$\%$ of sites $L A \geq 2$ mm, median (IQR) & $5(0-12)$ & $4(0-12)$ & 0.577 & $6(0-14)$ & 0.730 \\
\hline Mesial sites only & $3(0-11)$ & $4(0-13)$ & 0.852 & $4(0-14)$ & 0.596 \\
\hline$\%$ of sites $L A \geq 3 \mathrm{~mm}$, median (IQR) & $0(0-4)$ & $0(0-4)$ & 0.305 & $0(0-4)$ & 0.602 \\
\hline Mesial sites only & $0(0-4)$ & $0(0-3)$ & 0.447 & $0(0-2)$ & 0.303 \\
\hline
\end{tabular}

${ }^{*} \mathrm{P}$ values from Mann Whitney $U$ test; ${ }^{\dagger} \mathrm{IQR}=$ inter-quartile range; ${ }^{\ddagger} \mathrm{PD}=$ probing depth; ${ }^{\alpha} \mathrm{LA}=$ loss of attachment; ${ }^{\beta} \mathrm{BOP}=$ bleeding on probing

Relevant demographic, medical and periodontal variables were compared for each of the above outcome groups. For each preterm birth cut-off and for the miscarriage group, those who experienced this outcome were compared with those who gave birth at 37 weeks gestation or over. The low birth weight group were compared with those where the baby was $2,500 \mathrm{~g}$ or over at birth. Differences between those that had experienced an adverse pregnancy outcome, as defined above, and those that had not were tested by: $t$-tests, for those variables approximating to a Normal distribution; Mann Whitney- $U$ (MWU) tests, for those variables that were not normally distributed; exact chi-square test for cate- gorical variables, unless numbers in each group were over 200 in which case chi-square tests were used.

Logistic regression analysis was employed to identify explanatory variables for poor pregnancy outcome, controlling for the effects of other explanatory covariates. For categorical pregnancy outcomes, step-wise logistic regression was performed. Variance inflation factors (VIFs) for independent variables specified in fitted models were assessed after each stage of linear regression analysis. Those variables that increased the mean VIF value were excluded separately in a stepwise fashion until all the variables in the model gave a low mean VIF value. The regression analysis was then 


\begin{tabular}{|c|c|c|c|c|c|c|}
\hline & $\begin{array}{c}\text { Non-low birth } \\
\text { weight delivery, } \\
n=3,492\end{array}$ & $\begin{array}{l}\text { Low birth } \\
\text { weight delivery, } \\
n=246\end{array}$ & $\begin{array}{l}\text { Pvalue } \\
\text { LBW vs } \\
\text { non-LBW }\end{array}$ & $\begin{array}{c}\text { Non-preterm } \\
\text { delivery, } \\
n=3,452\end{array}$ & $\begin{array}{c}\text { Miscarriage } \\
n=49\end{array}$ & $\begin{array}{c}\text { Pvalue } \\
\text { miscarriage } \\
\text { vs non-preterm }\end{array}$ \\
\hline$\%$ of sites with plaque, median $(\mathrm{IQR})^{+}$ & $53(34-72)$ & $57(39-73)$ & 0.064 & $53(34-72)$ & $52(37-77)$ & 0.806 \\
\hline Mesial sites only & $68(44-88)$ & $70(50-92)$ & 0.130 & 68 (44-89) & $69(45-92)$ & 0.716 \\
\hline Mean $\mathrm{PD}^{\ddagger}, \mathrm{mm}$, median (IQR) & $2.03(1.82-2.27)$ & $2.04(1.83-2.29)$ & 0.500 & $2.03(1.82-2.27)$ & $2.07(1.93-2.41)$ & 0.023 \\
\hline Mesial sites only & $2.44(2.20-2.76)$ & $2.46(2.19-2.79)$ & 0.805 & $2.44(2.19-2.76)$ & $2.63(2.36-2.95)$ & 0.003 \\
\hline Mean $L A^{\alpha}$, mm, median (IQR) & $0.23(0.09-0.45)$ & $0.22(0.08-0.45)$ & 0.488 & $0.23(0.09-0.45)$ & $0.32(0.16-0.57)$ & 0.053 \\
\hline Mesial sites only & $0.20(0.04-0.48)$ & $0.19(0.03-0.53)$ & 0.597 & $0.20(0.04-0.48)$ & $0.31(0.14-0.65)$ & 0.038 \\
\hline$\%$ of sites $B O P \beta$, median (IQR) & $21(11-37)$ & $21(11-36)$ & 0.655 & $22(11-37)$ & $22(12-40)$ & 0.674 \\
\hline Mesial sites only & $29(14-46)$ & $26(14-46)$ & 0.728 & $29(14-46)$ & $34(18-52)$ & 0.349 \\
\hline$\%$ of sites $P D \geq 4$ mm, median (IOR) & $4(2-9)$ & $4(0-10)$ & 0.442 & $4(2-9)$ & $7(2-13)$ & 0.045 \\
\hline Mesial sites only & $7(3-18)$ & $7(0-19)$ & 0.422 & $4(3-18)$ & $14(4-23)$ & 0.042 \\
\hline$\%$ of sites PD $\geq 5 \mathrm{~mm}$, median (IQR) & $0(0-4)$ & $0(0-3)$ & 0.282 & $0(0-4)$ & $0(0-4)$ & 0.908 \\
\hline Mesial sites only & $0(0-7)$ & $0(0-7)$ & 0.388 & $0(0-7)$ & $0(0-8)$ & 0.945 \\
\hline$\%$ of sites $L A \geq 2 \mathrm{~mm}$, median (IQR) & $5(0-12)$ & $4(0-13)$ & 0.369 & $5(0-12)$ & $8(4-17)$ & 0.014 \\
\hline Mesial sites only & $3(0-11)$ & $3(0-12)$ & 0.628 & $3(0-11)$ & $7(0-16)$ & 0.009 \\
\hline$\%$ of sites $L A \geq 3 \mathrm{~mm}$, median (IQR) & $0(0-4)$ & $0(0-4)$ & 0.875 & $0(0-4)$ & $2(0-6)$ & 0.152 \\
\hline Mesial sites only & $0(0-4)$ & $0(0-3)$ & 0.822 & $0(0-4)$ & $0(0-3)$ & 0.700 \\
\hline
\end{tabular}

${ }^{\bar{*}} \mathrm{P}$ values from Mann Whitney $\mathrm{U}$ test; ${ }^{\dagger} I Q R=$ inter-quartile range; ${ }^{\dagger} \mathrm{PD}=$ probing depth; ${ }^{\alpha} \mathrm{LA}=$ loss of attachment; ${ }^{\beta} \mathrm{BOP}=$ bleeding on probing

repeated to form a single regression model. The direction and strength of association was assessed by generating odds ratios, the precision of which could be measured by $95 \%$ confidence intervals. Squared correlation coefficients $\left(R^{2}\right)$, derived from the final multiple regression model, were used to judge the proportional explanatory value of the model.

Combinations of probing depth and/or loss of attachment cutoff points were used to identify the approximate $7.5 \%$ of subjects at either end of the range of periodontal disease health and severity. Frequencies were determined and statistical tests were performed to identify differences between the two groups.

\section{RESULTS}

Baseline demographic and periodontal data were collected for 3,823 subjects. However, the pregnancy outcome data were not available for 85 subjects $(2.2 \%)$ and these subjects were excluded from the analyses. This resulted in a complete dataset for 3,738 subjects. Of these, 286 subjects (7.7\%) gave birth at less than 37 weeks gestation (preterm birth group) and 49 subjects (1.3\%) had a late miscarriage (between 12 and 24 weeks gestation) or an intra-uterine death at 24 weeks gestation or over (miscarriage/stillbirth group).

The main demographic and obstetric data of all subjects are summarised in Table 1. In addition this table compares these variables for those subjects who experienced a preterm birth $(7.7 \%$ of the population) and those that had a non-preterm birth. Of the 286 subjects that had a preterm birth, 112 had a baby at less than 32 weeks gestation and were termed the extreme preterm group (3.0\% of the study population). Of those who had a preterm birth, a higher proportion were from Black ethnic groups (42\% versus 27\%, $P<0.001)$, a lower proportion were from socioeconomic groups 1 and 2 (47\% versus 54\%, $P=0.037)$. A higher proportion took some form of medication in their first trimester of pregnancy (37\% versus $31 \%, P=0.015)$ and a higher percentage took antibiotics during this time (15\% versus $12 \%)$, but this just failed to reach statistical significance $(P=0.058)$. There was also a larger proportion of subjects with previous obstetric complications in the group who delivered prematurely. Similar differences in ethnicity, use of antibiotics and other medication use and poor previous obstetric history were observed when comparing the group that had an extreme preterm birth with those that had a non-preterm delivery. In addition the extreme preterm group had a lower proportion of subjects in their first pregnancy (37\% versus $47 \%, P=0.019$ ) and a higher proportion of subjects that had a urinary tract infection in the first 12 weeks of gestation (15\% versus 9\%, $P=0.018$ ). Conversely, there was no statistically significant difference in the proportions of subjects from the three socioeconomic groups compared with the group that had a non-preterm birth.

Table 2 demonstrates the demographic and obstetric characteristics of the group that had a low birth weight (LBW) delivery (less than 2,500 g) and those that had a late miscarriage (between 12 and 24 weeks gestation). The LBW group is compared with the non-LBW group and the miscarriage group is compared with the non-preterm group (birth at 37 weeks gestation or above). The subjects who experienced a LBW birth had a higher proportion of subjects from Black ethnic groups, a higher proportion of subjects from lower socioeconomic groups and a higher proportion of smokers during pregnancy ( $20 \%$ versus $14 \%, P=0.016$ ). In addition this LBW group had a higher proportion who had a urinary tract infection, took antibiotics or other medication in the first trimester of pregnancy and higher proportions of subjects who had experienced adverse pregnancy outcome in previous pregnancies.

Table 5 Logistic regression model for variables influencing the pregnancy outcome of preterm birth with $P$ values, odds ratios and 95\% confidence intervals

\begin{tabular}{l|c|c|c}
\hline & Odds ratio & $95 \% \mathrm{Cl}$ & $P$ value \\
\hline Oral steroids taken in $1^{\text {st }}$ trimester & 5.48 & $1.94-15.45$ & 0.001 \\
\hline Steroids taken before delivery & 3.18 & $0.83-12.16$ & 0.088 \\
\hline Antibiotics taken before delivery & 2.03 & $1.20-3.45$ & 0.005 \\
\hline Non-white ethnicity & 1.28 & $1.05-1.56$ & 0.019 \\
\hline History of previous preterm birth & 1.26 & $1.05-1.56$ & $<0.001$ \\
\hline Medication taken in $1^{\text {st }}$ trimester & 1.26 & $0.95-1.92$ & 0.098 \\
\hline Lower socioeconomic status & 1.11 & $1.00-1.05$ & 0.021 \\
\hline Pseudo $R^{2}=0.032$ & & &
\end{tabular}


Table 6 Logistic regression model for variables influencing the pregnancy outcome of low birth weight birth with $P$ values, odds ratios and $95 \%$ confidence intervals

\begin{tabular}{l|c|c|c}
\hline & Odds Ratio & $95 \% \mathrm{Cl}$ & $P$ value \\
\hline $\begin{array}{l}\text { Oral steroids taken in } 1^{\text {st }} \text { trimester } \\
\text { History of previous low birth }\end{array}$ & 4.45 & $1.55-12.76$ & 0.003 \\
$\begin{array}{l}\text { weight birth } \\
\text { History of previous preterm birth }\end{array}$ & 3.52 & $1.66-7.43$ & $<0.001$ \\
\hline History of previous miscarriage & 1.61 & $1.79-4.90$ & $<0.001$ \\
\hline Antibiotics taken in $1^{\text {st }}$ trimester & 1.38 & $1.01-1.88$ & 0.010 \\
\hline Lower socioeconomic status & 1.10 & $1.01-1.20$ & 0.001 \\
\hline Lower maternal age & 1.02 & $0.99-1.05$ & 0.058 \\
\hline Number of previous pregnancies & 0.83 & $0.72-0.96$ & 0.002 \\
\hline Pseudo $R^{2}=0.054$ & & &
\end{tabular}

Pseudo $R^{2}=0.054$

Table 7 Logistic regression model for variables influencing the pregnancy outcome of miscarriage/stillbirth with $P$ values, odds ratios and $95 \%$ confidence intervals

\begin{tabular}{l|c|c|c}
\hline & Odds Ratio & $95 \% \mathrm{Cl}$ & $P$ value \\
\hline Oral steroids taken in $1^{\text {st }}$ trimester & 11.52 & $2.32-57.19$ & 0.003 \\
\hline Antibiotics taken in $1^{\text {st }}$ trimester & 2.75 & $1.41-5.35$ & 0.003 \\
\hline $\begin{array}{l}\text { Increased mean probing depth } \\
\text { (mesial sites) }\end{array}$ & 2.54 & $1.20-5.39$ & 0.015 \\
\hline History of previous miscarriage & 2.02 & $1.00-4.11$ & 0.053 \\
\hline Lower socioeconomic status & 1.19 & $1.00-1.42$ & 0.045 \\
\hline Non-white ethnicity & 1.12 & $1.03-1.23$ & 0.013 \\
\hline Increasing age & 1.08 & $1.02-1.15$ & 0.013 \\
\hline Pseudo
\end{tabular}

Pseudo $R^{2}=0.087$

The group of 49 subjects (1.3\% of the study population) that had a late miscarriage were found to have a higher mean age (31.9 versus 29.8 years, $P=0.012$ ), contained a higher proportion of subjects from Black ethnic groups, a lower proportion of subjects from socioeconomic groups 1 and 2, a lower proportion of primigravida subjects, a higher proportion of subjects who took antibiotics or other medication in their first trimester of pregnancy and a higher percentage of subjects with a previous history of preterm birth and miscarriage.

Tables 3 and 4 demonstrate the periodontal data for all the previously discussed adverse pregnancy outcome groups: there were no statistically significant differences in any of the periodontal variables when comparing the non-preterm group with either the preterm subjects or the extreme preterm subjects. Likewise the low birth weight (LBW) group also demonstrates no statistically significant differences when compared with the non-LBW group. However the proportion of sites with plaque tended to be higher in the LBW group $(P=0.064)$

Table 4 also compares the periodontal data for the subjects who had a late miscarriage with those that did not have a preterm birth. The median mean probing depth for all and mesial sites was higher $(P=0.023$ and $P=0.003$ respectively) in the miscarriage group. The median mean loss of attachment for all sites was also higher in the miscarriage group, approaching statistical significance $(P=$ 0.053). When only mesial sites were compared, the mean loss of attachment was statistically significantly greater in the miscarriage group $(P=0.038)$. Subjects who experienced a miscarriage also had a higher proportion of sites probing $4 \mathrm{~mm}$ or greater. In addition the proportion of sites with loss of attachment of $2 \mathrm{~mm}$ or greater was larger in the miscarriage group.

Regression and further analysis for the direction of associations (Table 5) revealed that the following variables were associated with a preterm birth: previous history of preterm birth; taking oral steroids in the first trimester; taking antibiotics at or just before delivery; non-White ethnicity; lower socioeconomic status; taking oral steroids or any other medication or in the first trimester. The variable that appeared to have the largest effect (the largest odds ratio) in this model was taking oral steroids in the first trimester of pregnancy, with an odds ratio of 5.48 .

The regression model to describe variables influencing the outcome of low birth weight is shown by Table 6 . As seen with the regression model for preterm birth, history of poor pregnancy outcome, medication (antibiotics or oral steroids) taken in the first trimester of pregnancy and lower socioeconomic status are factors associated with low birth weight birth. In addition, lower number of previous pregnancies and lower maternal age adversely affect this pregnancy outcome.

Table 7 shows the results for regression with the variable of miscarriage/stillbirth. Miscarriage was associated with: taking oral steroids or antibiotics in the first trimester; increased age; nonWhite ethnicity; history of previous miscarriage; lower socioeconomic status. Higher mean probing depth (mesial sites) was also found to be associated with having a late miscarriage or stillbirth. Again taking oral steroids in the first trimester had the highest odds ratio in this model. In the regression models, the squared correlation coefficients were low.

The number of subjects in the periodontally healthy group was 277 (7.4\% of the cohort population). These subjects were defined as having less than 10\% of sites with probing depth of $3 \mathrm{~mm}$ or greater and less than 5\% of sites $2 \mathrm{~mm}$ or more loss of attachment. There were 269 subjects (7.2\%) in the group with the most severe periodontal disease. These subjects had more than five sites with probing depth of greater than or equal to $5 \mathrm{~mm}$ and more than three sites with greater than or equal to $3 \mathrm{~mm}$ loss of attachment.

Table 8 compares the main demographic and obstetric variables of the periodontally healthy with those with the most severe periodontal disease. The data for all subjects are included for comparison. It was found that the 'diseased' group had a higher mean age and had a higher proportion of subjects from Black ethnic groups. The proportion of smokers in pregnancy was lower in the periodontally healthiest group (13\% versus $21 \%, P=0.010$ ). In the periodontally healthy group, there was a higher proportion of primigravida subjects. There were no statistically significant differences between the two groups in the incidence of previous adverse pregnancy outcome. This table also demonstrates the proportions of subjects from each periodontal health group who experienced an adverse pregnancy outcome. These proportions were not statistically significantly different between groups, but extreme preterm birth (less than 32 weeks gestation) and late miscarriage tended towards being more common in the group with the most severe periodontal disease.

\section{DISCUSSION}

In the study presented here, analysis revealed that ethnicity, socioeconomic status, medication and previous poor obstetric outcome were associated with preterm birth at less than 37 weeks gestation and low birth weight at less than 2,500 g. All these variables could be regarded as 'classical' obstetric risk factors, as previously discussed. However there appeared to be no relation between preterm birth or low birth weight birth and periodontal health in this population using either single variable comparisons or multiple regression analyses. The squared correlation coefficients for the preterm birth and low birth weight models was extremely low indicating a low contribution of the factors in the model to preterm birth. This may highlight the idiopathic nature of adverse pregnancy outcome. ${ }^{11}$

When the outcome of late miscarriage was assessed not only did expected obstetric risk factors appear to be associated, but also that of poorer periodontal health in this small number of subjects, 


\begin{tabular}{|c|c|c|c|c|}
\hline & $\begin{array}{c}\text { Perio. healthy } \\
\text { (healthy) } \\
n=277\end{array}$ & $\begin{array}{c}\text { Severest perio. } \\
\text { (disease), } \\
n=269\end{array}$ & $\begin{array}{c}P \text { value } \\
\text { (healthyv } \\
\text { disease) }\end{array}$ & $\begin{array}{c}\text { All subjects, } \\
n=3,738\end{array}$ \\
\hline Age, years, mean (SD) & $28.6(5.8)$ & $32.0(5.1)$ & $<0.001^{*}$ & $29.9(5.5)$ \\
\hline \multicolumn{5}{|l|}{ Ethnicity, $n(\%)$} \\
\hline White & 203 (73.3) & $126(46.8)$ & & $2,330(62.3)$ \\
\hline Black & $44(15.9)$ & $116(43.1)$ & $<0.001$ & $1,055(28.2)$ \\
\hline Other & $30(10.8)$ & $27(10.0)$ & & $353(9.5)$ \\
\hline \multicolumn{5}{|l|}{ Socioeconomic group, $n(\%)$} \\
\hline $1 / 2$ & $159(57.4)$ & $131(48.7)$ & & $1,994(53.3)$ \\
\hline $3 / 4 / 5$ & $91(32.9)$ & $110(40.9)$ & 0.108 & $1,422(38.0)$ \\
\hline others & $27(9.7)$ & $28(10.4)$ & & $322(8.6)$ \\
\hline Smokers in pregnancy, $n(\%)$ & $36(13.0)$ & $56(20.8)$ & 0.010 & $543(14.5)$ \\
\hline $1^{\text {st }}$ pregnancy, $n(\%)$ & $149(53.8)$ & $100(37.1)$ & $<0.001$ & $1,749(46.7)$ \\
\hline Previous preterm delivery, $n(\%)$ & $15(5.4)$ & $17(6.3)$ & 0.394 & $155(4.2)$ \\
\hline Previous miscarriage/stillbirth, $n(\%)$ & $48(17.3)$ & $57(21.2)$ & 0.150 & $705(18.9)$ \\
\hline$<37$ weeks gestation, $n(\%)$ & $20(7.2)$ & $24(8.9)$ & 0.283 & $286(7.7)$ \\
\hline$<32$ weeks gestation, $n(\%)$ & $4(1.4)$ & $9(3.3)$ & 0.120 & $112(3.0)$ \\
\hline$<2500 \mathrm{~g}$ birth weight, $n(\%)$ & $22(7.9)$ & $23(8.6)$ & 0.459 & $246(6.7)$ \\
\hline Miscarriage, n (\%) & $1(0.4)$ & $6(2.2)$ & 0.057 & $49(1.3)$ \\
\hline
\end{tabular}

shown especially by the higher mean probing depth in this group. Likewise when those with the best periodontal health were compared with those with the most severe periodontal disease there were no differences in the proportions of subjects from each group that experienced either preterm birth or extreme preterm birth (less than 32 weeks gestation). However, 2.2\% of subjects with the severest periodontal disease experienced a late miscarriage whereas in the periodontally healthiest this figure was $0.4 \%$. This difference just failed to reach statistical significance $(P=0.057)$. Miscarriage (or spontaneous abortion) and stillbirth are pregnancy outcomes that have not been reported in previous studies that have investigated periodontal disease and pregnancy outcome. Although very few subjects experienced a late miscarriage or stillbirth, it must be considered that those experiencing an early miscarriage will not have been recruited and that the highest rate of miscarriage occurs early in pregnancy. ${ }^{11}$ It may be hypothesised that late miscarriage represents a more extreme version of preterm birth. The higher squared correlation coefficients in these models indicate that these factors explain variation in miscarriage to a greater extent than the factors implicated in the preterm birth model.

The variables of antibiotics and steroids taken before delivery were also associated with poorer pregnancy outcome, possibly due to the administration of these drugs to prevent preterm birth after premature rupture of membranes. ${ }^{19}$ Interestingly, these pharmacological agents, when taken in the first trimester of pregnancy, also appeared to be associated with adverse outcome. It may be that these drugs were given to prevent or treat urinary tract infection, which in itself has been associated with poor obstetric outcome ${ }^{20}$ and perhaps treating urinary tract infection at an early stage of pregnancy is critical to prevent more extreme adverse pregnancy outcome. However, this study failed to find such an association between pregnancy outcome and reported urinary tract infection, perhaps due to problems in diagnosing maternal genito-urinary tract infection, which can often be subclinical. ${ }^{21}$ Other medication taken in early pregnancy was also associated with poor outcome: it may be regarded as a surrogate marker for medical problems which may themselves affect pregnancy outcome.
Although poorer periodontal health did show some association with late miscarriage, there was no evidence that either poor oral hygiene or bleeding on probing were associated with any poor pregnancy outcome. The lack of an association with bleeding on probing may have been complicated by a known association between pregnancy and increased gingival inflammation. ${ }^{22-26}$

Pregnancy outcome data collection was very successful with only $2.2 \%$ of subjects missing outcome data. It is difficult to compare the population in this study with either other UK or US maternity populations, however some data are available. In the study group, $17 \%$ of subjects were under 25 years of age, $61 \%$ were between 25 and 34 years and 21\% were 35 and over at baseline assessment. In the population reported in the NHS maternity statistics for England 1994-95, ${ }^{27}$ 27\% were under 25 years, 61\% were between 25 and 34 years and 11\% were 35 years or over, at delivery. The proportion of women in their first pregnancy was 45\% between 1994 and 1995, similar to the figure for this study of 47\%. The rate of preterm birth (birth at less than 37 weeks gestation) in this study was 7.7\% which appears to be comparable with the rate reported for England in 1997 to 1998 of 7.0\%. ${ }^{28}$ The study population appears to be similar to a English maternity population in all comparable variables except that of age: there was a larger proportion of subjects from the higher age bracket than from the national statistics.

The level of periodontal disease reported in this study was similar to that found in the UK as a whole. The Adult Dental Health Survey (ADHS) study ${ }^{29}$ was analysed by gender and age group, but not separately, therefore males and females aged 16 to 44 years could be compared with the pregnant females in this study who were aged 14 to 45 years. It is important to note that the ADHS assessed mesial and distal sites, therefore comparisons were made between the ADHS and data from this study for mesial sites alone. It was found that $65 \%$ of our population had one or more sites with visible plaque and this figure is similar to that in the ADHS study of 71\%. Of the study described herein, $12 \%$ of pregnant women had one or more deep pockets (6 $\mathrm{mm}$ or more) compared with $3 \%$ of subjects with pocketing of at least $5.5 \mathrm{~mm}$ in one or more sites in the ADHS study. Likewise there was a higher proportion of preg- 
nant subjects with one or more sites probing $4 \mathrm{~mm}$ or more (77\% compared with $48 \%$ of ADHS subjects with at least one site with $3.5 \mathrm{~mm}$ or greater). Whereas $16 \%$ of our population had one or more sites with loss of attachment of $4 \mathrm{~mm}$, this figure was $29 \%$ (3.5 mm or more) in the ADHS study. Periodontal variables in the ADHS tended to have lower values for female subjects compared with males. However, it may be postulated that the higher proportion of subjects with deep periodontal pockets, but similar loss of attachment, in the present study may be due to the influence of pregnancy hormones on development of false pocketing and consequently increased probing depths. ${ }^{23}$

The previously reported periodontal disease and adverse pregnancy outcome papers ${ }^{1-4}$ studied different populations to that of this study. Both the studies from the USA ${ }^{1,2}$ involved subjects who were younger, had a higher proportion of subjects from Black ethnic groups (approximately 60\% for Offenbacher's population and $82 \%$ for Jeffcoat's population versus $28 \%$ for the study presented here) and a higher proportion smoking in pregnancy. It was also stated that these populations were generally of a low socioeconomic status.

Davenport's population, from the catchment area of the Royal London Hospital, Whitechapel were primarily (54\%) Bangladeshi in origin and of lower socioeconomic status than our prospective study population; however, the prevalence of adverse obstetric outcome was similar to ours. ${ }^{4}$ Both the case-control studies ${ }^{1,4}$ use the definition of preterm low birth weight for case subjects. This may not be a suitable definition for adverse obstetric outcome.

Although the study presented here and the previous work of Offenbacher et al. ${ }^{1}$ differ in design, it is possible to compare periodontal disease levels. In this study, the mean probing depth for the group with the most severe periodontal disease was $2.78 \mathrm{~mm}$ and for the periodontally healthiest group this figure was 1.59 $\mathrm{mm}$. These results were lower than the mean probing depths seen in Offenbacher's case-control study in which the group with the healthiest periodontal status (the primiparous controls with a 'normal' pregnancy outcome) had a mean probing depth of 2.87 $\mathrm{mm}$. Offenbacher's case (preterm and low birth weight) group had a mean probing depth of $3.17 \mathrm{~mm}$. Offenbacher's study also reported that the group with the lowest mean proportion of sites with $4 \mathrm{~mm}$ or more loss of attachment was the control group, with $17 \%$ of sites. In our cohort study, the group with the most severe periodontal disease had an average of $4 \%$ of sites with loss of attachment of $4 \mathrm{~mm}$ or more. If only mesial sites are assessed in this study, the mean probing depth of the $7.5 \%$ of subjects with the severest periodontal disease was $3.52 \mathrm{~mm}$, which is more comparable with the mean probing depth for case subjects in the USA study. The periodontal disease status of the subjects from Alabama USA ${ }^{2}$ was also more severe than in this UK population. Only $1.4 \%$ of our population had loss of attachment of $3 \mathrm{~mm}$ or greater in 25\% or over of sites, whereas one-third of the Alabama subjects had this level of disease. It has been reported that there is a high incidence of early-onset periodontitis amongst AfricanAmericans in certain regions of USA ${ }^{30}$ and this may explain, in part, the higher prevalence of periodontal disease in the North Carolina and Alabama studies. Davenport et al. ${ }^{4}$ also gave some indication of the level of periodontal disease in their population: the control subjects had a mean probing depth of $3.85 \mathrm{~mm}$ and the case subjects had a mean probing depth of $3.72 \mathrm{~mm}$. Again the levels of periodontal disease in the study presented here were lower than in the previous UK case-control study.

The latest study to be reported is from Chile. ${ }^{3}$ This prospective (and intervention) study presented results for 351 subjects aged 18 to 35 years. This population had a lower proportion of subjects in their first pregnancy (approximately 25\% versus 47\% for this UK population), and a higher proportion that smoked during pregnancy (approximately 25\% versus 15\%). The baseline mean probing depth and mean loss of attachment were both higher than for this study (2.71-2.94 mm versus $2.03 \mathrm{~mm} ; 1.75 \mathrm{~mm}-1.86 \mathrm{~mm}$ versus $0.23 \mathrm{~mm}$ ). Lopez found an association between preterm low birth weight birth and poorer periodontal health but again the population varied both in terms of demographic factors and periodontal health compared with this UK population.

A limitation of this study was that some of the baseline data relied on self-report from the subjects, which may have biased the results especially for such information as smoking during pregnancy. The limitations of relying on self-report have been highlighted for investigating relationships between smoking and periodontal disease and smoking and adverse pregnancy outcome. ${ }^{31,32}$ Scott and co-workers demonstrated that the use of a biochemical marker, such as cotinine, gives a much more reliable indication of a subject's exposure to cigarette smoke. Likewise, Ness found that smoking did not appear to be involved in the aetiology of miscarriage if data was taken only by self-reporting, however there was an association between these two factors when urinary cotinine was analysed. ${ }^{32}$ There is an indication that the level of smoking during pregnancy in our study was lower than that previously reported. Owen and co-workers found that approximately one-quarter of women self-reported smoking during pregnancy ${ }^{33}$ whereas only $14 \%$ of women in this study reported smoking. It has been reported that a lack of accurate data on the level smoking may bias apparent associations between periodontal disease and systemic conditions such as cardiovascular diseases and preterm birth. ${ }^{34}$

In addition, the study presented here used a method of partial mouth recording of periodontal variables, despite reports that the use of a partial mouth recording method can result in the underestimation of the level of disease. ${ }^{35}$ However it was imperative to keep the examination time and potential discomfort to a minimum for the subjects to maximise recruitment and therefore the power of the study. In addition the full mouth mesiobuccal-buccal measuring technique has been shown to an effective way of determining the prevalence of periodontal disease compared with some other partial recording protocols. ${ }^{36}$

One limitation regarding data collection was the method of gathering pregnancy outcome data. The Guy's and St Thomas' maternity database (Terranova) was the prime source of information. This database relied on input of data from midwives on maternity wards and often data were missing. However the research midwife made every effort to pursue missing data, which resulted in the extremely high rate of outcomes collected.

Another source of potential error is the large number of analyses performed in this study. Multiple testing can introduce bias into the results, overestimating the significance of statistically significant results. ${ }^{37}$ One method to correct for this would be to use the Bonferroni correction which would reduce the $P$ value for which results would be accepted as statistically significant, this would have implications for the observed association between some measures of periodontal disease and late miscarriage.

In conclusion, there does not appear to be an association between maternal periodontal disease in the first trimester of pregnancy and preterm birth or low birth weight birth in this population. However there is a relationship, although weak, between poor periodontal health and late miscarriage. Differences between the results in this study and previous reported studies may be due to differences in population, both in terms of periodontal health and the incidence of poor pregnancy outcome.

The authors wish to acknowledge the invaluable advice, assistance and cooperation of colleagues and support staff in the Department of Fetal Medicine and the Fetal Health Research Group, Guy's and St Thomas' Hospital Trust without which this study would have been impossible; particularly Dr Susan Bewley, Mr Darryl Maxwell and Professor Lucilla Poston. The authors also acknowledge the assistance of colleagues in the Department of Periodontology and Preventive Dentistry, GKT Dental Institute and Colgate-Palmolive, UK for supplying oral hygiene packs for the subjects. 
This work was undertaken with funding from the DHSC - London, Research and Development, Responsive Funding Programme. The views expressed in the publication are those of the authors and not necessarily those of the NHS or the Department of Health.

1. Offenbacher $\mathrm{S}, \mathrm{Katz} \mathrm{V}$, Fertik $\mathrm{G}$, et al. Periodontal infection as a possible risk factor for preterm low birth weight. J Periodontol 1996; 67: 1103-1113.

2. Jeffcoat M K, Geurs N C, Reddy M S, Cliver S P, Goldenberg R L, Hauth J C. Periodontal infection and preterm birth. JAm Dent Assoc 2001; 132: 875-888.

3. Lopez N J, Smith P C, Gutierrez J. Periodontal therapy may reduce the risk of preterm low birth weight in women with periodontal disease: a randomized controlled trial. J Periodonto/ 2002; 73: 911-924.

4. Davenport E S, Williams C E C S, Sterne J A C, Murad S, Sivapathasundram V, Curtis MA. Maternal periodontal disease and preterm low birth weight: case-control study. J Dent Res 2002; 81:313-318.

5. Madianos P N, Bobetsis G A, Kinane D F. Is periodontitis associated with an increased risk of coronary heart disease and preterm and/or low birth weight births? J Clin Periodonto/2002; 29(Suppl 3): 22-36.

6. World Health Organisation. International classification of diseases. 1975 revision. Volume 1. Geneva: WHO, 1977.

7. Wood N S, Marlow N, Costeloe K, Gibson A T, Wilkinson A R. Neurologic and developmental disability after extremely preterm birth. New Eng/ J Med 2000; 343: 378-384.

8. Barker D J P. Fetal and infant origins of adult disease. London: Br Med J 1990; 17:1111

9. Kramer M S, Demissie K, Yang H, Platt R W, Sauvé R, Liston $\mathrm{R}$. The contribution of mild and moderate preterm birth to infant mortality. J Am Med Assoc 2000; 284: 843-849.

10. Macfarlane A, Mugford M. Birth counts. Statistics of pregnancy and childbirth. 2 edn. Norwich: The Stationery Office. 2000.

11. Campbell S, Lees C. Obstetrics by ten teachers. 17 edn. New York: Arnold. 2000.

12. Genco R J. Current view of risk factors for periodontal diseases. J Periodonto/ 1996; 67: 1041-1049.

13. Ismail A I, Morrison E C, Burt B A, Caffesse R G, Kavanagh M T. Natural history of periodontal disease in adults: Findings from the Tecumseh Periodontal Disease Study: 1959-1987. J Dent Res 1990; 69: 430-435.

14. Preber $H$, Bergström J. Effect of non-surgical treatment on gingival bleeding in smokers and non-smokers. Acta Odontol Scand 1986; 44: 85-89.

15. Bergström J. Cigarette smoking as a risk factor in chronic periodontal disease. Community Dent Oral Epidemiol 1989; 17: 245-247.

16. Haber J, Wattles J, Crowley M, Mandell R, Joshipura K, Kent R L. Evidence for cigarette smoking as a major risk factor for periodontitis. J Periodonto/ 1993; 64: 16-23.

17. Snijders R J M, Noble P, Sebire N, Souka A, Nicolaides K H. UK multicentre project on assessment of risk of trisomy 21 by maternal age and fetal nuchal-translucency thickness at 10-14 weeks of gestation. Lancet 1998; 352:343-346.
18. Moore $\mathrm{S}$, Ide $\mathrm{M}$, Wilson $\mathrm{R}$ F, et al. Periodontal health of London women during early pregnancy. BrDent J 2001; 191: 570-573.

19. Goldenberg R L, Hauth J C, Andrews W W. Intrauterine infection and preterm delivery. New Eng/J Med 2000; 342: 1500-1507.

20. Minkoff H. Prematurity: Infection as an etiologic factor. Obstet Gynecol 1983; 62: $137-144$.

21. Hill G B. Preterm birth: Associations with genital and possibly oral microflora. Ann Periodontol 1998; 3: 222-232.

22. Silness J, Löe H. Periodontal disease in pregnancy, 3. Response to local treatment. Acto Odontol Scand 1966; 24: 747-759.

23. Cohen D W, Shapiro J, Friedman L, Kyle G C. Franklin S. A longitudinal investigation of the periodontal changes during pregnancy and fifteen months post-partum: Part 2. J Periodontol 1971; 42: 653-657.

24. Arafat A H. Periodontal status during pregnancy. J Periodontol 1974; 45: 641-643.

25. Samant A, Malik CP, Chabra S K, Devi P K. Gingivitis and periodontal disease in pregnancy. J Periodonto/ 1974; 47: 641-643.

26. Raber-Durlacher J E, van Steenbergen T J M, Van Der Velden U, de Graff J, Abraham-Inpijn L. Experimental gingivitis during pregnancy and post-partum: clinical, endocrinological, and microbiological aspects. J Clin Periodo/ 1994; 21: 549-558.

27. Lancucki L. (Ed.) NHS maternity statistics, England: 1989-90 to 1994-95. 1997 London: Department of Health, 1997.

28. Lancucki L. (Ed.) NHS Maternity Statistics, England: 1995-96 to 1997-98. London: Department of Health, 2001.

29. Kelly M, Steele J, Nutall N, et al. Adult Dental Health Survey. Oral Health in the United Kingdom 1998. London: Office for National Statistics, 2000

30. Oliver R C, Brown L J, Löe H. Periodontal diseases in the United States population. J Periodonto/ 1998; 69: 269-278.

31. Scott D A, Palmer R M, Stapleton J A. Validation of smoking status in clinical research into inflammatory periodontal disease. J Clin Periodo/ 2001; 28: 715-722.

32. Ness R B, Grisso J A, Hirschinger N, et al. Cocaine and tobacco use and the risk of spontaneous abortion. New Engl J Med 1999; 340: 333-339.

33. Owen $L$, McNeill A, Callum C. Trends in smoking during pregnancy in England, 1992-7: quota sampling surveys. Br Med J 1998; 317: 728.

34. Spiekerman CF, Hujoel P P, DeRouen TA. Bias induced by self-reported smoking on periodontitis-systemic disease associations. J Dent Res 2003; 82: 345-349.

35. Agerholm D M, Ashley FP. Clinical assessment of periodontitis in young adults evaluation of probing depth and partial recording methods. Community Dent Oral Epidemio/ 1996; 24: 56-61.

36. Kingman A, Albandar J. Methodological aspects of epidemiological studies of periodontal disease. Periodontol 2000 2002; 29: 11-30.

37. Campbell M J, Machin D. Medical Statistics. 3rd edn, Chichester: John Wiley \&t Sons Ltd, 1999. 